\title{
CHANGES IN DORSAL NECK MUSCLE FUNCTION IN INDIVIDUALS WITH CHRONIC WHIPLASH-ASSOCIATED DISORDERS: A REAL-TIME ULTRASOUND CASE-CONTROL STUDY
}

\author{
Gunnel Peterson, David Nilsson, Simon Peterson, Asa Dedering, Johan Trygg, Thorne \\ Wallman and Anneli Peolsson
}

\section{Linköping University Post Print}

\section{Tweet}

N.B.: When citing this work, cite the original article.

Original Publication:

Gunnel Peterson, David Nilsson, Simon Peterson, Asa Dedering, Johan Trygg, Thorne Wallman and Anneli Peolsson, CHANGES IN DORSAL NECK MUSCLE FUNCTION IN INDIVIDUALS WITH CHRONIC WHIPLASH-ASSOCIATED DISORDERS: A REALTIME ULTRASOUND CASE-CONTROL STUDY, 2016, Ultrasound in Medicine and Biology, (42), 5, 1090-1102.

http://dx.doi.org/10.1016/j.ultrasmedbio.2015.12.022

Copyright: Elsevier

$$
\text { http://www.elsevier.com/ }
$$

Postprint available at: Linköping University Electronic Press

http://urn.kb.se/resolve?urn=urn:nbn:se:liu:diva-127550 
Changes in dorsal neck muscle function in individuals with chronic whiplash-associated disorders: a real-time ultrasound case-control study

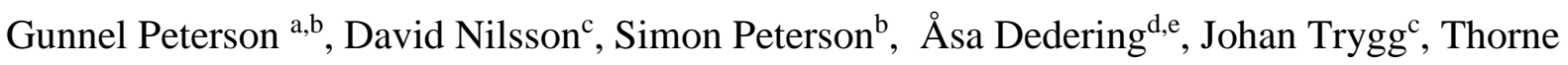
Wallman $^{\mathrm{a}, \mathrm{f}}$, Anneli Peolsson ${ }^{\mathrm{b}}$

${ }^{a}$ Centre for Clinical Research Sörmland, Uppsala University, Eskilstuna, Sweden

${ }^{\mathrm{b}}$ Department of Medical and Health Sciences, Division of Physiotherapy, Linköping

University, Linköping, Sweden

${ }^{\mathrm{c} C o m p u t a t i o n a l ~ L i f e ~ S c i e n c e ~ C l u s t e r ~(C L i C), ~ D e p a r t m e n t ~ o f ~ C h e m i s t r y, ~ U m e a ̊ ~ U n i v e r s i t y, ~}$ Sweden

${ }^{\mathrm{d}}$ Department of Neurobiology, Care Sciences and Society, Division of Physiotherapy, Karolinska Institutet, Sweden

e Department of Physical Therapy, Karolinska University Hospital, Sweden

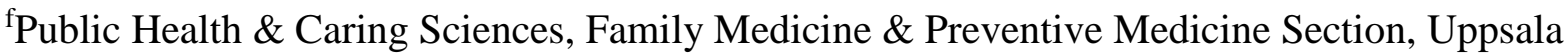
University, Sweden

Address correspondence to Gunnel Peterson, Department of Medical and Health Sciences, Division of Physiotherapy, Linköping University, SE-581 83 Linköping, Sweden. E-mail: gunnel.peterson@liu.se 


\section{ABSTRACT}

Impaired neck muscle function leads to disability in individuals with chronic whiplashassociated disorder (WAD), but diagnostic tools are lacking. In this study, deformations and deformation rates were investigated in five dorsal neck muscles during 10 arm elevations by ultrasonography with speckle tracking analyses. Forty individuals with chronic WAD (28 women and 12 men; mean age 37 years) and 40 healthy controls matched for age and sex were included. The WAD group showed higher deformation rates in the multifidus muscle during the first $(\mathrm{p}<0.04)$ and tenth (only women; $\mathrm{p}<0.01)$ arm elevations compared with the control group. Linear relationships between the neck muscles for the deformation rate (controls; $\mathrm{R}^{2}=0.24-0.82, \mathrm{WAD} ; \mathrm{R}^{2}=0.05-0.74$ ) and deformation of the deepest muscles (controls; $\mathrm{R}^{2}=0.61-0.32, \mathrm{WAD} ; \mathrm{R}^{2}=0.15-0.01$ ) were stronger for women in the control group versus women with WAD, indicating there is altered interplay between dorsal neck muscles in chronic WAD.

Keywords: Whiplash injury; ultrasonography; neck muscles; spine 


\section{INTRODUCTION}

The annual incidence of whiplash injury is $200-300$ per 100000 in the general population (Holm et al. 2008, Styrke et al. 2012) and is defined as a sudden acceleration-deceleration movement of the head that can cause both joints and soft tissue injuries in the neck (Siegmund et al. 2009). Despite decades of research, the mechanisms responsible for the burden in chronic whiplash-associated disorders (WAD) are not well understood and diagnostic tools are lacking. The neck muscles surrounding the cervical spine and the deep neck muscle layers play an important role in maintaining a stable base for the postural control of the neck (Mayoux-Benhamou et al. 1994, Panjabi 1992). Impaired ventral neck muscle function has been reported in chronic neck pain (Falla et al. 2004, Falla et al. 2011, Jull et al. 2004) and WAD (Cagnie et al. 2010, Elliott et al. 2010, Jull et al. 2004, Peterson et al. 2015a, Sterling et al. 2003), but the function of the neck extensor muscles in WAD are not as well studied. Elliott et al. (2008a) demonstrated fatty infiltrate in the extensor muscle in WAD using magnetic resonance imaging (MRI). Functional MRI studies have reported altered neck muscle activity after induced pain in healthy individuals (Cagnie et al. 2011) and in individuals with neck pain (O'Leary et al. 2011). Electromyography (EMG) studies have shown that not all dorsal muscles act synergistically as extensors; the splenius capitis muscle can activate during neck flexion in some healthy individuals (Keshner et al. 1989, Siegmund et al. 2007) and higher levels of extensor muscle co-activation in neck pain have been reported (Lindstrom et al. 2011). Surface EMG has demonstrated increased activity in superficial neck extensors in WAD (Bexander et al. 2012, Juul-Kristensen et al. 2013), but when controlling for differences in movement velocity, no differences were found between WAD and healthy controls (Vikne et al. 2013). Small invasive EMG studies have reported decreased and less defined activity in the deep semispinalis cervicis muscle in WAD (Schomacher et al. 2012), and the multifidus muscle was affected by eye movement 
(Bexander et al. 2012). Both the expensive MRI and invasive EMG are difficult to apply in routine clinical practice and MRI does not provide information on the interplay between muscle layers. Real-time ultrasound imaging measures the mechanical function in the muscle, the elongation and shortening of the muscle (i.e., deformation) and how fast the deformation occurs (i.e., deformation rate). This method has been used to detect altered ventral neck muscle function in individuals with chronic WAD (Peterson et al. 2015b) and altered muscle function in the semispinalis capitis muscle after decompression surgery for cervical disc disease (Peolsson et al. 2015). The strength of real-time ultrasound is that it can noninvasively evaluate both superficial and deep muscle function simultaneously. To the best of our knowledge, this method has not been applied to investigate dorsal neck muscle function in WAD.

The aim of the present study was two-fold: to compare mechanical neck muscle function, deformation, and deformation rate in five dorsal neck muscles in individuals with chronic WAD versus healthy controls during repetitive arm elevation, and to investigate if the interplay in deformation and deformation rate between these muscles differs between the WAD and control groups.

\section{METHODS}

\section{Participants}

Forty individuals (28 women and 12 men; mean age 37 years, SD 11.2) with chronic WAD, including 29 individuals with WAD grade II (neck pain and musculoskeletal signs) and 11 individuals with WAD grade III (neck pain plus neurological signs), were included in the study. The participants were recruited consecutively for ultrasound investigation among 
patients enrolled in a randomized controlled trial (Peolsson et al. 2013). Inclusion criteria were persistent symptoms associated with a whiplash injury 6 months to 3 years prior to study entry; WAD grade II or III; age $18-63$ years; persistent neck pain rated greater than $20 \mathrm{~mm}$ and/or neck disability index (NDI) (Vernon and Mior 1991) greater than 20\%; dominant neck pain on the right side of the neck; and right-handedness. Exclusion criteria were signs of traumatic brain injury at the time of whiplash injury; known or suspected serious pathology; previous fracture or luxation in the cervical spine; contraindication to exercise; neuromuscular diseases; rheumatologic disease; previous neck pain causing more than 1 month of sick leave in the year before the whiplash injury; severe mental illness; current alcohol or drug abuse; or an inability to understand spoken and written Swedish.

For comparison, 40 healthy controls matched for age and sex (mean age 37 years, SD 11.4) were recruited from university staff, hospital staff, and acquaintances. Exclusion criteria were present or past neck problems; trauma to the neck or head, including whiplash injury; neck or low back pain; rheumatologic or neurological disease; or generalized myalgia.

The baseline characteristics of the participants are provided in Table 1 . The study was approved by the Regional Ethics Review Board and was conducted according to the Declaration of Helsinki. Written informed consent was obtained from all participants. The study had no adverse effects.

\section{Ultrasound measurement}

To evaluate the dorsal neck muscles we used a B-mode, 2-D ultrasound Vivid-i scanner (GE Healthcare, Horten, Norway) and hand-held $12 \mathrm{MHz}$ linear array transducer (12L-RS, footprint $39 \mathrm{~mm}$, GE Healthcare, Horten, Norway) with high frame rate (235 frames/s). Five dorsal neck muscles (upper trapezius, splenius capitis, semispinalis capitis, semispinalis cervicis, and multifidus/rotatores) (Fig. 1a and 1b) were recorded during 10 repetitive arm 
elevations (Fig. 1c and 1d). Measurements were made from the ultrasound movies during the first and tenth arm elevations at the level of the $4^{\text {th }}$ cervical vertebrae, which was identified by palpation of the $\mathrm{C} 4$ spinous process.

\section{Speckle tracking}

Real-time ultrasound imaging of skeletal muscle is able to detect the unique speckle pattern in muscles and can be post-processed analyzed using the speckle tracking method based on an algorithm developed by Kanade-Lucas-Tomasi (Lucas and Kanade 1981, Tomasi and Kanade1991) and Farron et al. (2009). A region of interest (ROI) was manually placed in the recorded muscle images and made it possible to track the unique speckle pattern frame by frame through the ultrasound video sequence. Each ROI consisted of a large number of measuring points and was placed in the first frame in the "video" sequence, following the frame to frame deformation throughout the ultrasound imaging. When the speckle pattern changes length during muscle activity, so does the length of the ROI. This provides measurement of muscle deformation (elongation or shortening) and was calculated as the percentage change in the ROI from the first original frame length of the ROI (expressed as \% deformation). The muscle deformation rate was expressed as the deformation per time unit (\% deformation/s).

Three rectangular ROIs (each $10 \times 3.3 \mathrm{~mm}$ ) were manually placed longitudinal to the muscle fibers in each muscle; together, the three ROIs covered $30 \mathrm{~mm}$ of the muscle of interest. The areas under the deformation curves (Fig. 1e) were calculated to measure the muscle deformation. The trapezoidal rule was used as a basis for evaluating the area (Equation 1), where $\mathrm{A}$ is the area, $\mathrm{t}$ is time between samples, and $\mathrm{y}_{\mathrm{n}}$ is the present ROI position at sample point $\mathrm{n}$. The equation was modified to handle intersections with the $0 \%$ line. To estimate 
additional sample points, linear interpolation was used with adjusted t-values at intersections with the $0 \%$ line. Thus, the area under and the area above the $0 \%$ line could be separated.

$A=\frac{t}{2}\left(\mathrm{y}_{1}+2 \mathrm{y}_{2}+2 \mathrm{y}_{3}+. .+2 \mathrm{y}_{\mathrm{n}-2}+2 \mathrm{y}_{\mathrm{n}-1}+\mathrm{y}_{\mathrm{n}}\right) \quad$ (Equation 1$)$

The speckle tracking analysis method has been shown to have excellent test-retest reliability (ICC 0.71-0.99) (Peolsson et al. 2015), and the magnitude of muscle deformation was positively related to force measurements and progressive electrical stimulation (Lopata et al 2010).

\section{Other measurements}

Before ultrasound measurements, all participants completed a set of questionnaires asking about age, gender, average pain intensity over the prior week (visual analogue scale [VAS], 0 $=$ no pain, $100=$ worst imaginable pain $)($ Carlsson 1983), and neck disability $($ NDI, 0\% = no disability, $100 \%$ = highest score for disability) (MacDermid et al. 2009). Other baseline characteristics, such as WAD grade, body mass index (BMI), neck fatigue (Borg CR-10 scale, 0 = no fatigue, 10 = extremely strong fatigue) (Borg 1990), and activity level (activity index, 1 = inactivity, 2 = low activity, 3 = moderate activity, $4=$ high activity) (Kallings et al. 2008), were also recorded (Table 1).

\section{Test procedure}

The test procedure was designed to evaluate neck muscle function during repeated arm elevation. In our clinical experience, increased pain is commonly described in patients with WAD after arm lifts, and activity-related increases in pain have been reported (Sullivan et al. 2010). The participants stood in an upright and comfortable position, their feet behind a line marked on the floor, and performed 10 arm elevations from 0 to 90 degrees. Two qualified physiotherapists performed the ultrasound test; one completed the ultrasound examination 
and the other instructed the participants and assisted the ultrasound examiner. The ultrasound transducer was placed on the right side of the neck at the level of the $4^{\text {th }}$ cervical vertebrae and adjusted for clear ultrasound imaging of the five dorsal neck muscles and then, the test was performed. (Fig. 1c and 1d).

\section{Ultrasound analyses}

The post-processing speckle tracking methodology was provided with a program designed inhouse for Matlab 2014a (The Mathworks Inc, Natick, MA, USA). The area was based on the curve of the changes in deformation and calculated to evaluate muscle deformation (Fig. 1e). The deformation rate, is negative during shortening and positive during elongation, and was expressed as the root mean square (RMS), which gives information on the local muscle velocity of deformation. An independent researcher coded all ultrasound images with a number to ensure that the person with three years of experience in speckle tracking analysis was blinded to group affiliation during post-processing analysis.

\section{Statistical analyses}

Statistical analyses were performed using SPSS software (IBM SPSS, Statistics for windows, Version 22.0, Armonk, NY). The participants' demographic characteristics were compared between groups using the two-tailed unpaired Students t-test for parametric data. For nonparametric demographic data the chi-squared test was used, and physical activity levels and neck muscle fatigue were analyzed using the Mann Whitney U test (Field, 2009).

Deformation and deformation rate were normally distributed and parametric statistical tests were applied. Six outliers (defined as deviating more than three times the interquartile range) were detected in deformation, three in the WAD group (two men and one woman) and three in the control group (all men). Seven outliers were identified in deformation rate (one in the WAD group and six controls, all men). These outliers were excluded because they impacted 
the results of the analysis and statistics derived from data that include outliers may be misleading. A mixed design analysis of variance (ANOVA) with Bonferroni correction was used to evaluate between-subject factor of group (two levels: WAD and controls) and within group factor of deformation and deformation rate (five levels, one for each muscle), and the analyses were adjusted for the duration of each arm elevation and sex (Field, 2009). The assumptions of variance were violated (Levene's test $p<0.05$ ) in deformation (first arm elevation) and deformation rate (tenth arm elevation) therefore, the data were $\log ^{10}$ transformed (Field, 2009).

To evaluate the interplay between muscles, the statistical analyses were performed as follows. The first step was simple linear regression to investigate the relationships between pairs of muscles in individuals in the WAD and control groups regarding the total deformation area and the deformation rate (RMS). As men had much greater variation in deformation and deformation rate with many outliers, only women were further analyzed regarding the linear relationship between muscles and multivariate analyses. Adjusted $\mathrm{R}^{2}$ values were reported and the strength of the linear relationship reported as follows: weak, $0.1-0.3$; moderate, 0.31 - 0.6; strong, $0.61-0.9$ (Dancey and Reidy 2014). The second step was multivariate analysis able to analyze the highly correlated five muscle layers simultaneously (Simca 13.0) (Eriksson 2013). Principal component analysis (PCA) is designed to extract systematic variation in the dataset and was utilized to obtain an overview of the data. Partial least squares discriminant analysis (PLS-DA) is a regression extension of PCA that was used to analyze the differences between the WAD and control groups, and orthogonal partial least squares discriminant analysis (OPLS-DA) is able to improve interpretability (Eriksson 2013). The strength in the multivariate statistics is the possibility to identify underlying patterns in large datasets from complex neck muscle interaction data. The data analyzed with the multivariate techniques comprised 40 variables, including the total deformation area, 
elongation and shortening area, and deformation rate from the five dorsal neck muscles during the first and tenth arm elevations (4 deformation variables x 5 muscles x 2 arm elevations $=40$ variables). All possible two-way combinations of interaction terms, including quadratic terms, between these 40 variables were evaluated, resulting in a total of 820 variables. Each variable was mean centered and scaled to unit variance prior to calculating the interaction between the variables. The interaction can be defined as the element-wise multiplication (Equation 2) between variables $a$ and $b ; \bar{x}_{a}$ and $\bar{x}_{b}$ are the means of the two variables $a$ and $b$ and $s_{a}$ and $s_{b}$ are the standard deviations. The quadratic terms were logarithmically transformed with base 10 prior to further analysis.

$i_{a b}=\frac{a-\bar{x}_{a}}{s_{a}} \circ \frac{a-\bar{x}_{b}}{s_{b}}$

(Equation 2)

The explained variance in the X-matrix (deformation and deformation rate variables) was determined by $\mathrm{R}^{2} \mathbf{X}$, the explained variance in the $\mathrm{Y}$-matrix (control or WAD) by $\mathrm{R}^{2} \mathbf{Y}$, and the predictive explained variance in $\mathbf{Y}$ by $\mathbf{Q}^{2} \mathbf{Y}$. The maximum values is 1.0 and denotes a perfect model.

Statistical significance was set at $\mathrm{P} \leq 0.05$.

\section{RESULTS}

\section{Comparisons of deformation in the WAD and control groups}

We found no significant group by deformation interaction effect $(\mathrm{F}=0.2$ to $2.0, p>.10)$ or differences between groups ( $\mathrm{F}=0.02$ to $0.55, p>0.46)$, but a significant group by sex interaction effect for both the first $(\mathrm{F}=3.9, p<0.01)$ and tenth $(\mathrm{F}=2.7, p<0.04)$ arm elevations. Men in the control group had greater deformation in all muscles ( $F=11.3$ to 35.5, $p<0.001)$ compared to women, but this difference was not seen in the WAD group $(\mathrm{F}=1.3$ to $0.39, p>0.25)$. (Supplementary Table 1$)$. 
We found a significant group by deformation rate interaction effect for the first $(\mathrm{F}=3.3, p<$ $.04)$ and tenth $(\mathrm{F}=5.9, p<.01)$ arm elevation and a significant main effect between the sexes $(\mathrm{F}=25.0$ to $19.1, p<.001)$. The WAD group had higher deformation rates in the multifidus muscle during the first and tenth (only women) arm elevations compared to the control group. Men had a higher deformation rate in all muscles compared to women in both the WAD $(F=$ 5.6 to $7.4, p<.03)$ and control groups $(\mathrm{F}=18.9$ to $19.3, p<.001)$. (Supplementary Table 2$)$. Interplay in deformation between pairs of muscles in women in the WAD and control groups Women in the WAD group exhibited moderate relationships between more pairs of muscles during the first arm elevation compared to controls $\left(\mathrm{R}^{2}=0.32\right.$ to 0.50$)$. Compared to the WAD group, controls had stronger positive linear relationships between the two deepest neck muscles (semispinalis cervicis and multifidus) during the first $\left(\mathrm{R}^{2}=0.61 \mathrm{vs} . \mathrm{R}^{2}=0.15\right)$ and tenth arm elevations $\left(R^{2}=0.32\right.$ vs. $\left.R^{2}=0.01\right)($ Table $2 a)$.

Interplay in deformation rate between pairs of muscles in women in the WAD and control groups

In the control group, we found stronger positive relationships between the muscles during both the first and tenth arm elevations $\left(\mathrm{R}^{2}=0.24\right.$ to 0.76$)$ compared to the WAD group $\left(\mathrm{R}^{2}=\right.$ 0.05 to 0.74 ), except for trapezius/semispinalis cervicis and semispinalis capitis/semispinalis cervicis during the tenth arm elevation (Table $2 b$ ). In the control group, the deep multifidus muscle had a stronger relationship with the other four investigated muscles than in the WAD group during both the first $\left(\mathrm{R}^{2}=0.24\right.$ to 0.56 vs. 0.05 to 0.41$)$ and tenth arm elevations $\left(\mathrm{R}^{2}=\right.$ 0.49 to 0.68 vs. 0.07 to 0.64 ) (Fig. 2). 
PCA was used to compress the 40 deformation area and deformation rate variables into a model with four components and an $\mathrm{R}^{2} \mathrm{X}$ of 0.585 . The score plot of the two first components (Fig. 3a), explaining $35.0 \%$ and $8.7 \%$, respectively, is an overview in which each dot corresponds to one person. Several outliers (i.e., dots outside the elliptical 95\% confidence region) were seen, predominantly among males (colored in blue) with only one female outlier. Moreover, males (blue dots) were essentially positioned on the right side of plot, whereas females were on the left. No differences between individuals with WAD and controls were detected in any of the four PCA components when the color was set according to group status (WAD/control).

Similar to the first model, PCA modelling of the complete data set with interaction terms (40 +820 variables) revealed that men exhibited a much larger variation (not shown) with many severe outliers. Consequently, the more homogenous female group was analyzed using PLSDA to find underlying structures that could separate patients from controls. Four out of 56 individuals were considered to be outliers (three WAD and one control) and were removed from further modelling. Only a weak relationship was found $\left(\mathrm{R}^{2} \mathrm{Y} 0.36\right.$ and $\left.\mathrm{Q}^{2} \mathrm{Y}=-0.22\right)$ between the deformation areas/rates and their interactions. Any attempt to add model components resulted in further worsening of the prediction efficiency $\mathrm{Q}^{2} \mathrm{Y}$.

Guided by the results of the univariate analysis of the deformation rate in the first and tenth elevations, in which the WAD group had significantly higher rates for the multifidus muscle, attempts were made to only include deformation rates and their interactions in the subsequent OPLS-DA modelling, which only included females and excluded the same individuals as the previous model. The best model only included strain rate deformations, as no interaction terms improved the model. The final model using the ten deformation rate variables (for the 
five muscles and first and tenth elevations) had an $R^{2} Y$ of 0.468 and $Q^{2} Y$ of 0.158 using one predictive and three orthogonal components. The loading plot (Fig. 3b) shows the relationship between the deformation rate variables and their impact on group status (WAD/control) y. The main contributors to separating WAD from controls are the multifidus deformation rates for the first and tenth elevations. The cross-validated score plot (Fig. 3c) did not exhibit a clear separation between patients and controls, but WAD (in red) resided primarily on the right side of the plot.

\section{DISCUSSION}

The main result from this study was a significant difference in deformation rate with a higher rate in the deepest multifidus muscle in individuals with WAD compared to healthy controls during the first and tenth (only women) arm elevations. There were also differences in deformation and the deformation rate for women regarding the interplay between muscle pairs. Regarding deformation, we identified a stronger positive linear relationship between the two deepest muscles in women in the control group compared to women in the WAD group. During the first and tenth arm elevations, women in the control group had a stronger positive linear relationship between the deformation rates of most of the investigated dorsal neck muscles compared to women in the WAD group. Men had much greater variations in mechanical neck muscle function but subgroup analyses of men were not possible due to too few men being included in the study. We found no other differences in interactions between muscles.

The deformation rate measures the rate during shortening and elongation deformation and was higher in the multifidus muscle in the WAD group. We speculate that a higher deformation rate indicates a muscle with less smooth activation, and that higher and 
oscillating rates may indicate ineffective muscle function. The interplay between the multifidus and the other four neck muscles had a weaker relationship in women in the WAD group, indicating an irregular interplay between the dorsal neck muscles, especially between superficial and deep neck muscles. Other studies have reported impaired neck muscle function in the deepest muscles; reduced activity in the semispinalis cervicis after induced pain in healthy subjects (Cagnie et al. 2011), altered activity in the multifidus during neck rotation in combination with eye movement in WAD subjects and authors speculated it could indicate less muscular support to stabilize the cervical spine (Bexander et al. 2012), and that higher amount of fatty infiltrate in the multifidus in women with WAD compared to women with insidious-onset neck pain (Elliott et al. 2008b) may be the results of structural damage, nerve injury or disuse of the muscle.

There were no differences between the WAD and control groups in the deformation of the five dorsal muscles. Large variation between individuals was observed with large standard deviations in deformation group data (Supplementary file 1). For women, a strong positive linear relationship was found between the deepest neck muscles (semispinalis cervicis and multifidus) in the control group, but not in the WAD group. This finding is in accordance with an ultrasound study of the interplay between ventral neck muscles (Peterson et al. 2015a) in which an individual muscle pattern was obtained with a stronger linear relationship between ventral neck muscles in healthy controls compared to individuals with WAD. The neck muscle layers support the cervical spine and the deep neck muscles in particular are involved in the intersegmental motion that is very important for postural control (Panjabi 1992, Mayoux-Benhamou et al. 1994). Increased motion in the lower cervical spine was observed among significantly more women with chronic WAD (Kristjansen et al. 2003) than non-traumatic neck pain, and reduced head steadiness was related to increased neck pain and dizziness in individuals with chronic WAD (Woodhouse et al. 2010). Moreover, Elliott et al. 
revealed a larger cross-sectional area in the multifidus muscles in women with chronic WAD than healthy controls (Elliot et al. 2008a) and non-specific neck pain (Elliot et al. 2008b), which reflects the higher amount of fatty infiltrate in the extensor neck muscles in WAD. Speculation as to the cause of fatty infiltrate in neck muscles in WAD involves a persistent inflammatory response to injured neck tissues, minor nerve injury, and/or disuse of the muscles. The increased cross-sectional area in the multifidus muscle (Elliott et al. 2008a) may also indicate overuse of the multifidus muscle with weaker interplay with the other neck muscles and higher deformation rate. The direct attachment of the multifidus to cervical facet capsules (Andersson et al. 2005) may be a source of increased neck pain in WAD, especially if the muscle has a higher deformation rate and weaker interplay with the other neck muscle layers. The present study investigated mechanical neck muscle function during a postural task in which the deep neck muscles are assumed to maintain a stable cervical spine (Panjabi 1992, Peterson 2004), and it seems reasonable that these muscles and the deep ventral muscles (Peterson et al. 2015a) need to be activated to support the cervical spine for postural control. The present study demonstrated altered function in the deep dorsal neck muscles in women with chronic WAD, which may decrease muscular support in the maintenance of a stable cervical spine and explain the persistent pain and disability in WAD. The findings are important for diagnosis and the development of exercise programs for individuals with chronic WAD.

The higher values and greater variations in both deformation and deformation rate among men indicate different mechanical muscle function compared to women, but only 12 men were included in the study, which is not enough for subgroup analyses of men. Men with WAD and healthy men also had a larger spread in interactions between ventral neck muscles compared to women (Peterson et al. 2015b). The differences in muscle characteristics, with larger muscles size and greater strength in men compared to women (Cote 2012), may 
explain the greater variations in interactions between dorsal neck muscles. To date, few studies investigating neck extensor muscles have included men. Only women have been investigated for fatty infiltrate (Elliott et al. 2008a) and superficial (Juul-Kristensen et al. 2013) and deep neck muscle activation (Schomacher et al. 2012). Some small studies have had an unequal distribution of men and women in the control group compared to the intervention group (Bexander et al. 2012, O'Leary et al. 2011), and small sample sizes in studies with more equal gender distribution (Cagnie et al. 2011, Vikne et al. 2013) make it difficult to detect differences between males and females. To the best of our knowledge, no analyses of sex have been reported. Further studies are needed to increase our knowledge about neck muscle function in men with chronic WAD.

Multivariate PCA and OPLSA-DA analyses allow the simultaneous investigation of many variables despite multicollinearity and the detection of underlying structures in the data set to find models (Eriksson 2013). In this study the analyses were applied to investigate deformation rate, total deformation area, and the elongation and shortening area in the five dorsal neck muscles. For women, the final model had limited predictive value but showed that the deformation rate in the multifidus muscle separates individuals with WAD and controls.

Studies of the neuromuscular control in the cervical spine have revealed a complex muscle activation pattern. Healthy individuals exhibit different preferred activation of the splenius as a neck extensor or flexor (Blouin et al. 2007, Keshner et al. 1989, Siegmund et al. 2007), synchronized neuronal drive between deep and superficial muscles (Blouin et al. 2007), and different activation strategies among individuals during a reflexive task (Siegmund et al. 2007). Individuals with WAD had less defined activity in the deep semispinalis capitis (Schomacher et al. 2012) and higher activity in the superficial neck extensor has been reported (Juul-Kristensen et al. 2013), but when controlling for movement velocity, the 
acceleration or deceleration peak in the splenius was not different from that of healthy controls (Vikne et al.2013). The different methods make it challenging to interpret results from different studies. EMG measures the muscle action potentials when the muscle fibers are neurologically activated, whereas ultrasound measures the mechanical muscle function. Different EMG tests result in different neck muscle activation patterns; if the head is firmly clamped and force applied to the head, preferred activation was seen in the neck muscles except for the splenius capitis (Keshner et al. 1989, Siegmund et al. 2007), whereas more individual muscle responses occur during reflexive movements (Siegmund et al. 2007). Taken together, the results of the present study suggest altered dorsal neck muscle function in women with chronic WAD in accordance with earlier observations of structural (Elliott et al. 2008a) and muscular impairment (Bexander et al. 2012, Cagnie et al. 2011) in these muscles.

\section{Limitations}

The present study has several limitations. Ultrasound measurements of local deformation in muscles have been validated successfully against force measurements (Lopata et al. 2010), but more studies are required to validate the method. The probe placement could also have been limited due to the lack of significant anatomical landmarks, though the $\mathrm{C} 4$ spinous process and vertebral column were used as reference points. In addition, men had greater deformation and higher deformation rates compared to women, with several severe outliers that excluded the men from further analyses. Thus, men likely have different mechanical muscle functions than women and studies including more men are warranted.

\section{CONCLUSION}

In conclusion, we showed that individuals with WAD have higher deformation rates in the multifidus muscle compared to healthy controls. In addition, the interplay between the deep dorsal neck muscles was weaker in women with WAD. The altered function of deep dorsal 
neck muscles in women with chronic WAD may decrease muscular support in the maintenance of a stable cervical spine and cause persistent pain and disability. To the best of our knowledge, no studies have previously investigated the deep dorsal neck muscles noninvasively during real-time motion in WAD. The results provide important information that can be used in the assessment and diagnosis of patients following whiplash trauma.

\section{Acknowledgement}

This study was financially supported by funding from the Swedish government in cooperation with the Swedish Social Insurance Agency through the REHSAM Foundation RS2010/009, the Swedish Research Council, Centre for Clinical Research Sörmland at Uppsala University Sweden, and Uppsala-Örebro Regional Research Council Sweden.

\section{Additional Information}

The authors declare no competing financial interests. 


\section{REFERENCES}

Anderson JS, Hsu AW, Vasavada AN. Morphology, architecture, and biomechanics of human cervical multifidus. Spine 2005;30(4):E86-91.

Bexander CS, Hodges PW. Cervico-ocular coordination during neck rotation is distorted in people with whiplash-associated disorders. Exp Brain Res 2012;217:67-77

Blouin JS, Siegmund GP, Carpenter MG, Inglis JT. Neural control of superficial and deep neck muscles in humans. J Neurophysiol 2007;98:920-8.

Borg G. Psychophysical scaling with applications in physical work and the perception of exertion. Scand J Work Environ Health 1990;16 Suppl 1:55-8.

Cagnie B, Dolphens M, Peeters I, Achten E, Cambier D, Danneels L. Use of muscle functional magnetic resonance imaging to compare cervical flexor activity between patients with whiplash-associated disorders and people who are healthy. Phys Ther 2010;90:1157-64.

Cagnie B, O'Leary S, Elliott J, Peeters I, Parlevliet T, Danneels L. Pain-induced changes in the activity of the cervical extensor muscles evaluated by muscle functional magnetic resonance imaging. Clin J Pain 2011;27:392-7.

Carlsson AM. Assessment of chronic pain. I. Aspects of the reliability and validity of the visual analogue scale. Pain 1983;16:87-101.

Cote JN. A critical review on physical factors and functional characteristics that may explain a sex/gender difference in work-related neck/shoulder disorders. Ergonomics. 2012;55(2):173-82.

Dancey CP, Reidy J. Statistics without maths for psychology. Sixth edition. 2014. ISBN: 9780273774990 
Elliott J, Jull G, Noteboom JT, Galloway G. MRI study of the cross-sectional area for the cervical extensor musculature in patients with persistent whiplash associated disorders (WAD). Man Ther. 2008a;13(3):258-65.

Elliott J, Sterling M, Noteboom JT, Darnell R, Galloway G, Jull G. Fatty infiltrate in the cervical extensor muscles is not a feature of chronic, insidious-onset neck pain. Clin Radiol. 2008b;63(6):681-7.

Elliott JM, O'Leary S, Sterling M, Hendrikz J, Pedler A, Jull G. Magnetic resonance imaging findings of fatty infiltrate in the cervical flexors in chronic whiplash. Spine 2010;35:948-54.

Eriksson L. Multi- and megavariate data analysis : basic principles and applications. 2013 Malmö: MKS Umetrics.

Falla D, Jull G, Hodges PW. Feedforward activity of the cervical flexor muscles during voluntary arm movements is delayed in chronic neck pain. Exp Brain Res 2004;157:43-8.

Falla D, O'Leary S, Farina D, Jull G. Association between intensity of pain and impairment in onset and activation of the deep cervical flexors in patients with persistent neck pain. Clin J Pain 2011;27:309-14.

Farron J, Varghese T, Thelen DG. Measurement of tendon strain during muscle twitch contractions using ultrasound elastography. IEEE Trans Ultrason Ferroelectr Freq Control 2009;56:27-35.

Field, A. Discovering statistics using SPSS. Los Angeles, SAGE; 2009. ISBN: 1847879063 
Holm LW, Carroll LJ, Cassidy JD, Hogg-Johnson S, Cote P, Guzman J, Peloso P, Nordin M, Hurwitz E, van der Velde G, Carragee E, Haldeman S. The burden and determinants of neck pain in whiplash-associated disorders after traffic collisions: results of the Bone and Joint Decade 2000-2010 Task Force on Neck Pain and Its Associated Disorders. Spine 2008;33:S52-9.

Jull G, Kristjansson E, Dall'Alba P. Impairment in the cervical flexors: a comparison of whiplash and insidious onset neck pain patients. Man Ther 2004;9:89-94.

Juul-Kristensen B, Clausen B, Ris I, Jensen RV, Steffensen RF, Chreiteh SS, Jorgensen MB, Sogaard K. Increased neck muscle activity and impaired balance among females with whiplash-related chronic neck pain: a cross-sectional study. J Rehabil Med 2013;45:376-84.

Kallings LV, Leijon M, Hellenius ML, Stahle A. Physical activity on prescription in primary health care: a follow-up of physical activity level and quality of life. Scand J Med Sci Sports 2008;18:154-61.

Keshner EA, Campbell D, Katz RT, Peterson BW. Neck muscle activation patterns in humans during isometric head stabilization. Exp Brain Res 1989;75:335-44.

Kristjansson E, Leivseth G, Brinckmann P, Frobin W. Increased sagittal plane segmental motion in the lower cervical spine in women with chronic whiplash-associated disorders, grades I-II: a case-control study using a new measurement protocol. Spine. 2003;28(19):2215-21.

Lindstrom R, Schomacher J, Farina D, Rechter L, Falla D. Association between neck muscle coactivation, pain, and strength in women with neck pain. Man Ther 2011;16:80-6.

Lopata RG, van Dijk JP, Pillen S, Nillesen MM, Maas H, Thijssen JM, Stegeman DF, de Korte CL. Dynamic imaging of skeletal muscle contraction in three orthogonal directions. J Appl Physiol 2010;109:906-15. 
Lucas BD, Kanade T. An Iterative Image Registration Technique with an Application to Stereo Vision. Procedings of the $7^{\text {th }}$ International Joint Conference on Artificial Intelligence 674-679, 1981.

MacDermid JC, Walton DM, Avery S, Blanchard A, Etruw E, McAlpine C, Goldsmith CH. Measurement properties of the neck disability index: a systematic review. The Journal of orthopaedic and sports physical therapy 2009;39:400-17.

Mayoux-Benhamou MA, Revel M, Vallee C, Roudier R, Barbet JP, Bargy F. Longus colli has a postural function on cervical curvature. Surg Radiol Anat 1994;16:367-71.

O'Leary S, Cagnie B, Reeve A, Jull G, Elliott JM. Is there altered activity of the extensor muscles in chronic mechanical neck pain? A functional magnetic resonance imaging study. Arch Phys Med Rehabil 2011;92:929-34.

Panjabi MM. The stabilizing system of the spine. Part I. Function, dysfunction, adaptation, and enhancement. J Spinal Disord 1992;5:383-9; discussion 97.

Peolsson A, Landen Ludvigsson M, Overmeer T, Dedering A, Bernfort L, Johansson G, Kammerlind AS, Peterson G. Effects of neck-specific exercise with or without a behavioural approach in addition to prescribed physical activity for individuals with chronic whiplash-associated disorders: a prospective randomised study. BMC Musculoskelet Disord 2013;14:311-17.

Peolsson A, Peolsson M, Jull G, Lofstedt T, Trygg J, O'Leary S. Preliminary evaluation of dorsal muscle activity during resisted cervical extension in patients with longstanding pain and disability following anterior cervical decompression and fusion surgery. Physiotherapy 2015;101:69-74

Peterson BW. Current approaches and future directions to understanding control of head movement. Prog Brain Res 2004;143:369-81. 
Peterson G, Dedering A, Andersson E, Nilsson D, Trygg J, Peolsson M, Wallman T, Peolsson A. Altered ventral neck muscle deformation for individuals with whiplash associated disorder compared to healthy controls - A case-control ultrasound study. Man Ther 2015a;20:319-27.

Peterson G, Nilsson D, Trygg J, Falla D, Dedering A, Wallman T, Peolsson A. Novel insights into the interplay between ventral neck muscles in individuals with whiplashassociated disorders. Sci Rep. 2015b;5:15289

Schomacher J, Farina D, Lindstroem R, Falla D. Chronic trauma-induced neck pain impairs the neural control of the deep semispinalis cervicis muscle. Clin Neurophysiol 2012;123:1403-8.

Siegmund GP, Blouin JS, Brault JR, Hedenstierna S, Inglis JT. Electromyography of superficial and deep neck muscles during isometric, voluntary, and reflex contractions. J Biomech Eng 2007;129:66-77.

Siegmund GP, Winkelstein BA, Ivancic PC, Svensson MY, Vasavada A. The anatomy and biomechanics of acute and chronic whiplash injury. Traffic injury prevention 2009;10:101-12.

Sterling M, Jull G, Vicenzino B, Kenardy J, Darnell R. Development of motor system dysfunction following whiplash injury. Pain 2003;103:65-73.

Styrke J, Stalnacke BM, Bylund PO, Sojka P, Bjornstig U. A 10-year incidence of acute whiplash injuries after road traffic crashes in a defined population in northern Sweden. Pm R 2012;4:739-47.

Sullivan MJ, Lariviere C, Simmonds M. Activity-related summation of pain and functional disability in patients with whiplash injuries. Pain 2010;151:440-6.

Tomasi C, Kanade T. Detection and Tracking of Point Features, Computer Science Department, Carnegie Mellon University, April, 1991 
Vernon H, Mior S. The Neck Disability Index: a study of reliability and validity.

J Manipulative Physiol Ther. 1991;14:409-15.

Vikne H, Bakke ES, Liestol K, Engen SR, Vollestad N. Muscle activity and head kinematics in unconstrained movements in subjects with chronic neck pain; cervical motor dysfunction or low exertion motor output? BMC Musculoskelet Disord 2013;14:314.

Woodhouse A, Liljeback P, Vasseljen O. Reduced head steadiness in whiplash compared with non-traumatic neck pain. J Rehabil Med. 2010;42(1):35-41. 
Table 1. Baseline characteristics of participants in the study.

\begin{tabular}{|c|c|c|c|}
\hline & WAD $(n=40)$ & Healthy controls $(\mathrm{n}=40)$ & $P$-value \\
\hline Female, n (\%) & $28(70 \%)$ & $28(70 \%)$ & 1.0 \\
\hline WAD grade II/III, n & $29 / 11$ & 0 & \\
\hline Age, years & $37.4(11.2)$ & $37.4(11.4)$ & 1.0 \\
\hline Injury duration ${ }^{\mathrm{a}}$, months & $21.2(8.5)$ & 0 & \\
\hline BMI male, $\mathrm{kg} / \mathrm{m}^{2}$ & $25.0(4.8)$ & $26.3(3.6)$ & 0.48 \\
\hline BMI female, $\mathrm{kg} / \mathrm{m}^{2}$ & $24.5(6.4)$ & $22.5(2.5)$ & 0.14 \\
\hline Physical activity level ${ }^{\mathrm{b}}$, median (range) & $2.0(2.0-3.75)$ & $3.5(4.0-4.0)$ & 0.001 \\
\hline Neck Disability Index ${ }^{c}$ & $32.4(13.9)$ & $1.4(1.8)$ & $<0.001$ \\
\hline Pain previous week ${ }^{\mathrm{d}}(\mathrm{VAS})$ & $45.9(18.7)$ & $1.1(2.2)$ & $<0.001$ \\
\hline Fatigue $^{\mathrm{e}}$ (Borg), median (range) & $3.3(2.0-5.0)$ & $0.1(0.0-0.0)$ & $<0.001$ \\
\hline
\end{tabular}

a) Months since whiplash injury, range 6 to 36 months.

b) Physical activity level over the last year; $1=$ inactivity, $2=$ low activity, $3=$ moderate activity, $4=$ high activity.

c) $0-100 \%$, higher scores represent higher disability.

d) Average pain in the prior week, range 0-100 mm, higher rating represents higher pain intensity.

e) CR 1-10; anchored with $1=$ no fatigue, $10=$ extremely strong fatigue.

Data are given as mean (SD) unless otherwise noted. BMI, body mass index; VAS, visual analog scale. 
Table 2a. Linear relationships in deformation between muscle pairs for women.

\begin{tabular}{|c|c|c|c|c|c|c|c|c|c|c|c|c|c|c|c|c|c|c|c|c|c|c|c|}
\hline & \multicolumn{11}{|c|}{ First arm elevation women } & \multicolumn{12}{|c|}{ Tenth arm elevation women } \\
\hline & \multicolumn{5}{|c|}{ Control group } & \multicolumn{6}{|c|}{ WAD group } & \multicolumn{6}{|c|}{ Control group } & \multicolumn{6}{|c|}{ WAD group } \\
\hline TR & & .32 & .03 & .05 & -.04 & TR & & .33 & .07 & .32 & .13 & TR & & .24 & .37 & -.01 & -.05 & TR & & .50 & .22 & .17 & .14 \\
\hline SP & .32 & & .02 & .07 & .06 & SP & .33 & & .28 & .36 & .16 & SP & .24 & & .22 & .16 & .02 & SP & .50 & & .11 & .07 & -.08 \\
\hline Scap & .03 & .02 & & .07 & .24 & Scap & .06 & .28 & & .02 & .47 & Scap & .37 & .22 & & .04 & .06 & Scap & .22 & .11 & & .40 & .08 \\
\hline Scerv & .05 & .07 & .07 & & .61 & Scerv & .32 & .36 & .02 & & .15 & Scerv & -.01 & .16 & .04 & & .32 & Scerv & .17 & .07 & .40 & & .01 \\
\hline \multirow[t]{2}{*}{ MF } & -.04 & .06 & .24 & .61 & & MF & .13 & .16 & .47 & .15 & & MF & -.05 & .02 & .06 & .32 & & MF & .14 & -.08 & .08 & .01 & \\
\hline & TR & SP & Scap & Scerv & MF & & TR & SP & Scap & Scer & MF & & & SP & Scap & Scerv & MF & & TR & SP & Scap & Scerv & MF \\
\hline
\end{tabular}

Data are adjusted $\mathrm{R}^{2}$ values. Grey shading indicates a moderate relationship $\left(\mathrm{R}^{2}=0.30-0.60 ; p<0.02\right)$ and black shading a strong relationship $\left(\mathrm{R}^{2}=0.61 ; p<0.001\right)$ between muscle pairs. Abbreviations: TR, trapezius; SP, splenius capitis; Scap, semispinalis capitis; Scerv, semispinalis cervicis; MF, multifidus/rotatores. 
Table 2b. Linear relationships in deformation rate between muscle pairs for women.

\begin{tabular}{|c|c|c|c|c|c|c|c|c|c|c|c|c|c|c|c|c|c|c|c|c|c|c|c|}
\hline \multicolumn{12}{|c|}{ First arm elevation women } & \multicolumn{12}{|c|}{ Tenth arm elevation women } \\
\hline \multicolumn{7}{|c|}{ Control group } & \multicolumn{5}{|c|}{ WAD group } & \multicolumn{6}{|c|}{ Control group } & \multicolumn{6}{|c|}{ WAD group } \\
\hline TR & & .76 & .73 & .28 & .24 & TR & & .61 & .28 & .24 & .07 & TR & & .71 & .61 & .24 & .49 & TR & & 63 & .21 & .31 & .11 \\
\hline SP & .76 & & .82 & .55 & .33 & SP & .61 & & .52 & .37 & .05 & SP & .71 & & .66 & .64 & .68 & SP & .63 & & .44 & .45 & .07 \\
\hline Scap & .73 & .82 & & .57 & .38 & Scap & .28 & .52 & & .33 & .17 & Scap & .61 & .66 & & .49 & .58 & Scap & .21 & .44 & & .74 & .43 \\
\hline Scerv & .28 & .55 & .57 & & .56 & Scerv & .24 & .37 & .33 & & .41 & Scerv & .24 & .64 & .49 & & .65 & Scerv & .31 & .45 & .74 & & .64 \\
\hline MF & .24 & .33 & .38 & .56 & & MF & .07 & .05 & .17 & .41 & & MF & .49 & .68 & .58 & .65 & & MF & .11 & .07 & .43 & .64 & \\
\hline & TR & SP & Scap & cer & MF & & TR & SP & Scap & Scerv & MF & & TR & SP & Scap & Scerv & MF & & TR & SP & Scal & Scerv & MF \\
\hline
\end{tabular}

Data are adjusted $\mathrm{R}^{2}$ values. Grey shading indicates a moderate relationship $\left(\mathrm{R}^{2}=0.30-0.60 ; p<0.02\right)$ and black shading a strong relationship $\left(\mathrm{R}^{2}=0.61-0.82 ; p<0.001\right)$ between muscle pairs. Abbreviations: TR, trapezius; SP, splenius capitis; Scap, semispinalis capitis; Scerv, semispinalis cervicis; MF, multifidus/rotatores. 


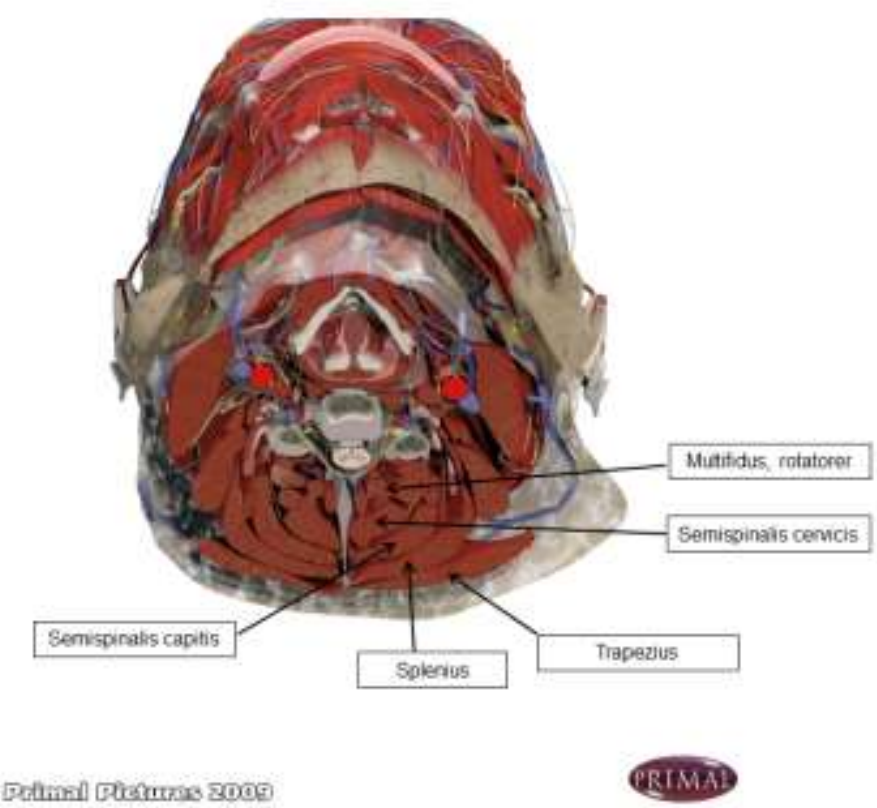

Fig. 1a Dorsal neck muscles

The five dorsal neck muscles of interest were the upper trapezius, splenius capitis, semispinalis capitis, semispinalis cervicis, and multifidus/rotatores (credit: Primal Pictures Ltd, 19 November 2015). 


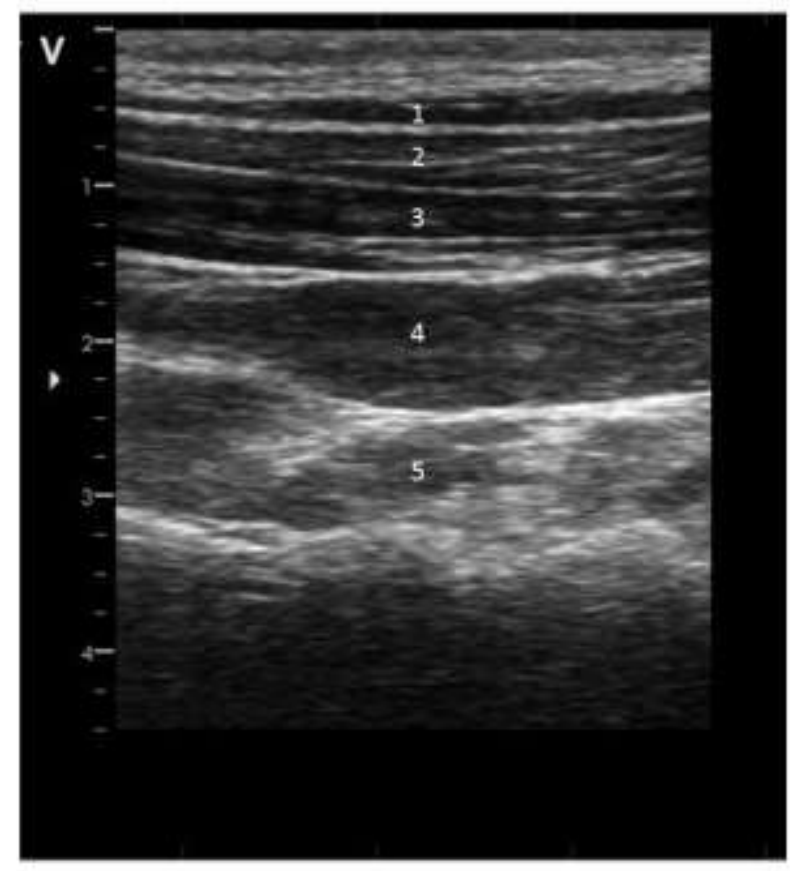

Fig. 1b Ultrasound image of the dorsal neck muscles

The image shows a longitudinal ultrasound B-mode projection. The specific muscles are numbered as follows: 1 , trapezius; 2 , splenius; 3 , semispinalis capitis; 4 , semispinalis cervicis, 5, multifidus/rotatores. 


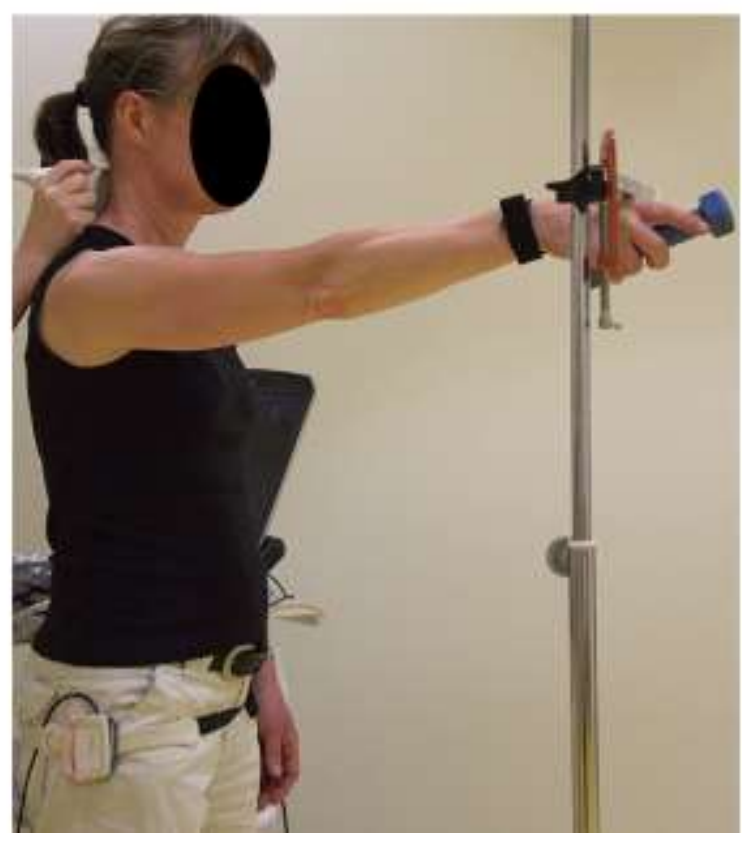

Fig.1c Ultrasound imaging of dorsal neck muscles

The test was standardized as follows. A custom-made contact switch was fastened to the participant's right hip and right wrist, allowing synchronized data between arm movement and ultrasound measurements. The right arm was raised to an adjustable horizontal bar fixed at 90 degree arm elevation, which was measured by a goniometer when the index finger touched the bar. Each participant was instructed to hold their head steady and look at the bar during the test. The participants held a $0.5 \mathrm{~kg}$ (women) or $1 \mathrm{~kg}$ (men) weight in their right hand and were told to move their arm in a smooth motion and raise it with the first beat, and then lower it to the switch contact in the next beat. A metronome was set at 40 beats per minute to maintain a steady pace. Each participant practiced the test with the left arm to familiarize themselves with the test. 


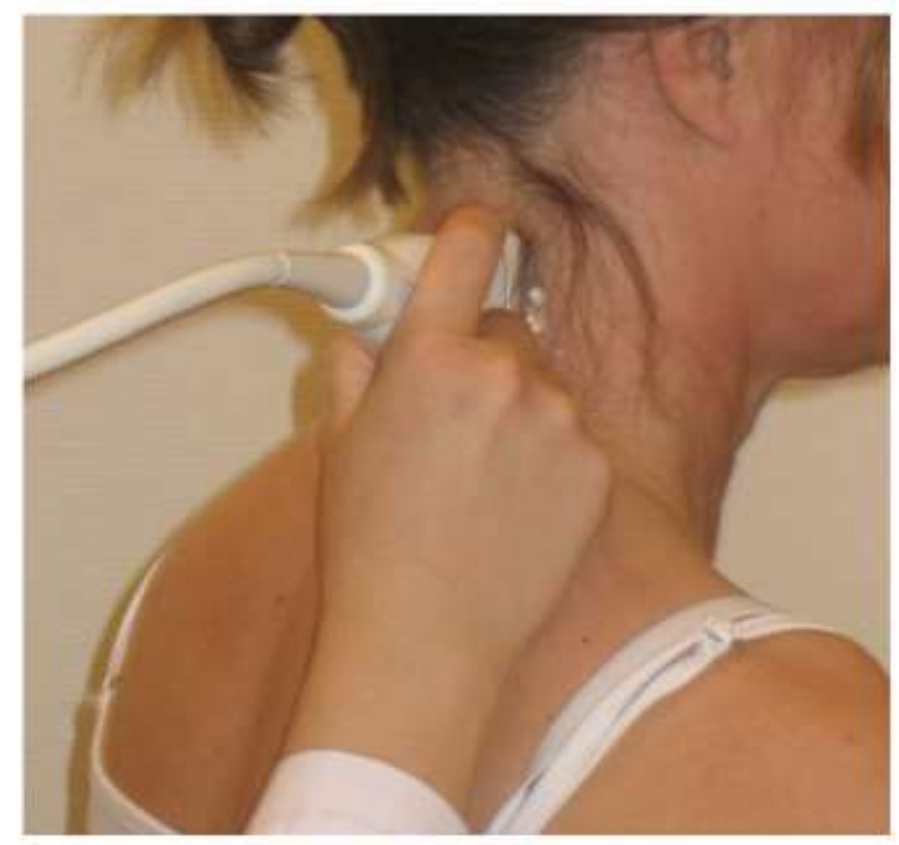

Fig 1d. Position of the ultrasound transducer

The ultrasound transducer was positioned on the right side of the neck. First, the transducer was positioned in a transverse orientation at the level of the $4^{\text {th }}$ cervical vertebrae for identification of neck muscle layers and bony landmarks. Next, the transducer was rotated $90^{\circ}$ to the longitudinal position to ensure an optimal image plane for the dorsal neck muscles. 


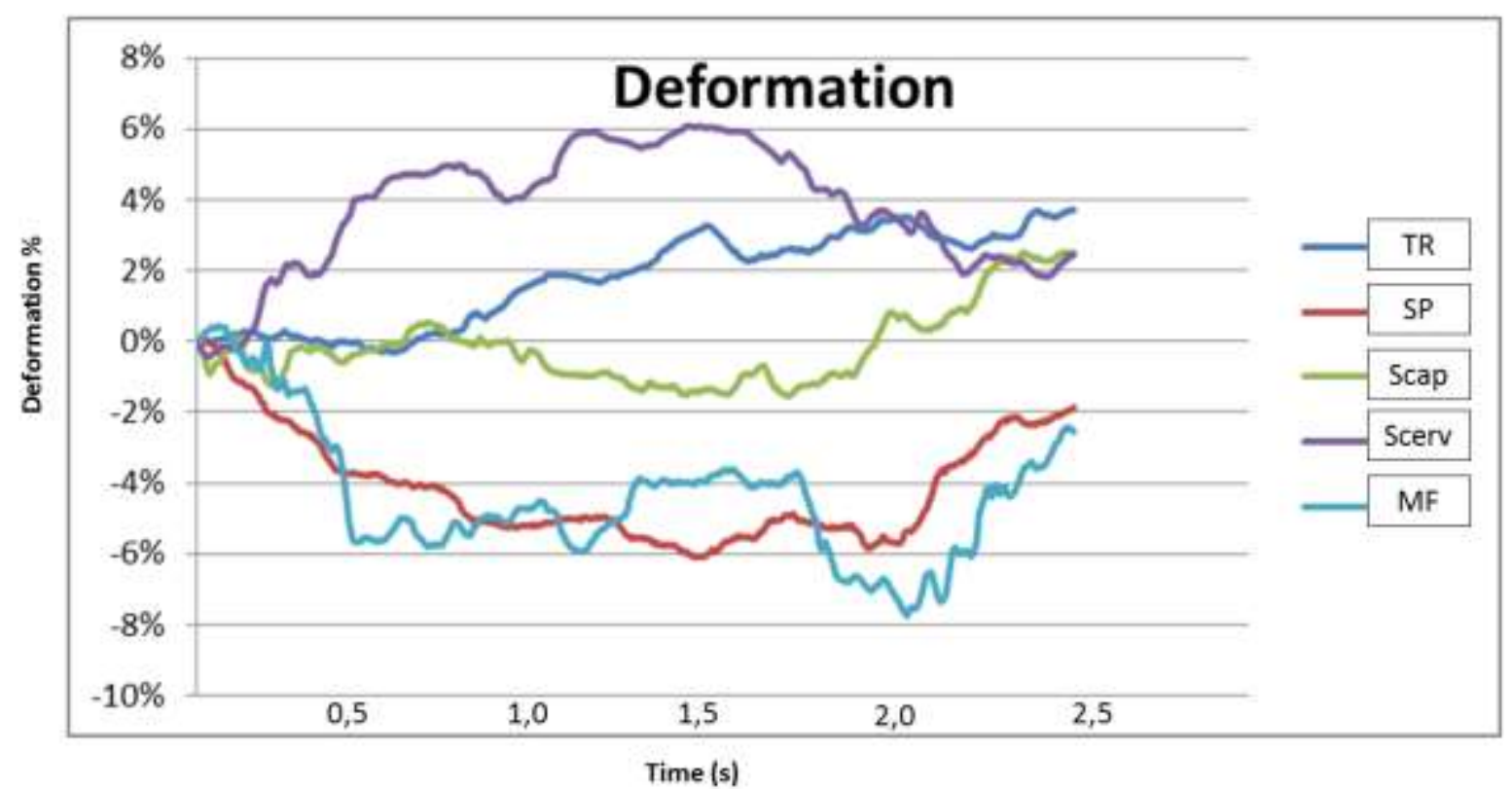

Fig. 1e. Muscle deformation areas

Different muscle deformation areas in five dorsal neck muscles during one arm elevation in a single participant. Each line denotes the changes in the ROI (deformation \%) in one muscle during one arm elevation. The negative values (area below zero) denote muscle shortening and the positive values (area above zero) denote muscle elongation. The total area (sum of negative and positive areas) denotes the total muscle deformation. When the line crosses the $0 \%$ line, the muscle switches from shortening to elongation, or vice versa. Abbreviations: TR, trapezius; SP, splenius capitis; Scap, semispinalis capitis; Scerv, semispinalis cervicis; MF, multifidus/rotatores 

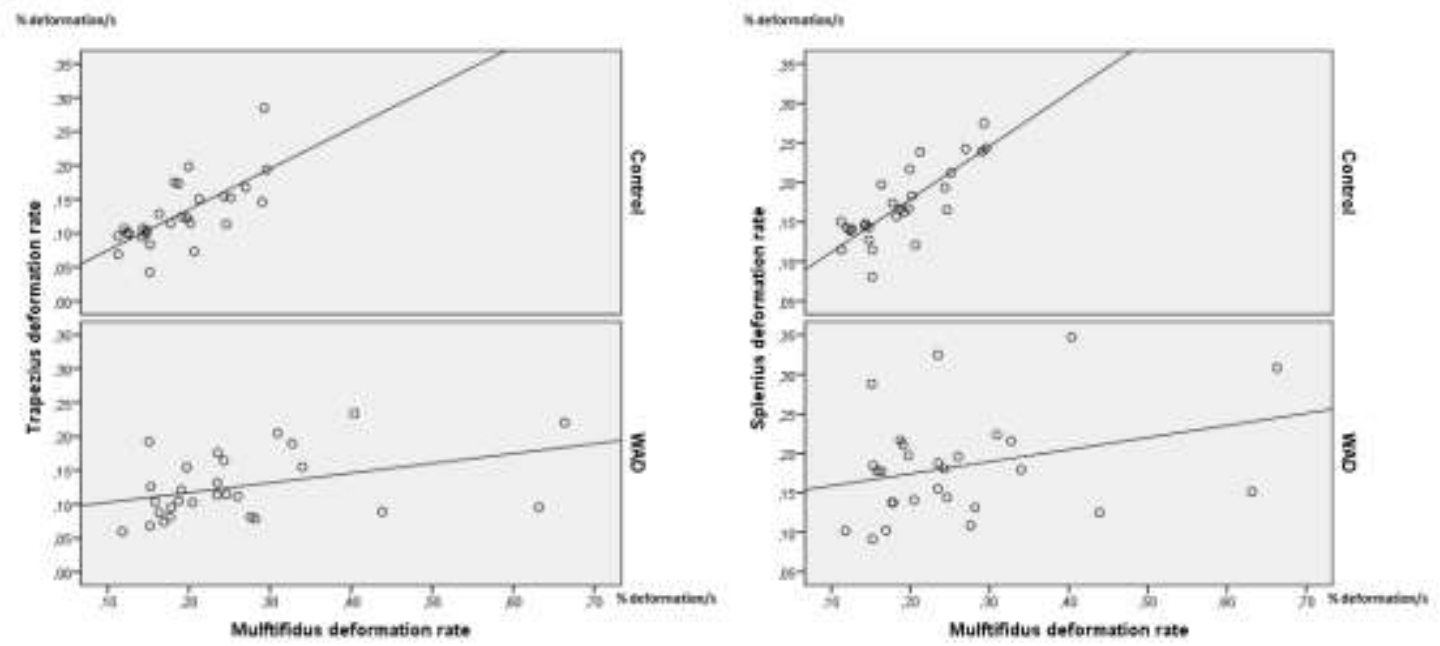

a)

b)
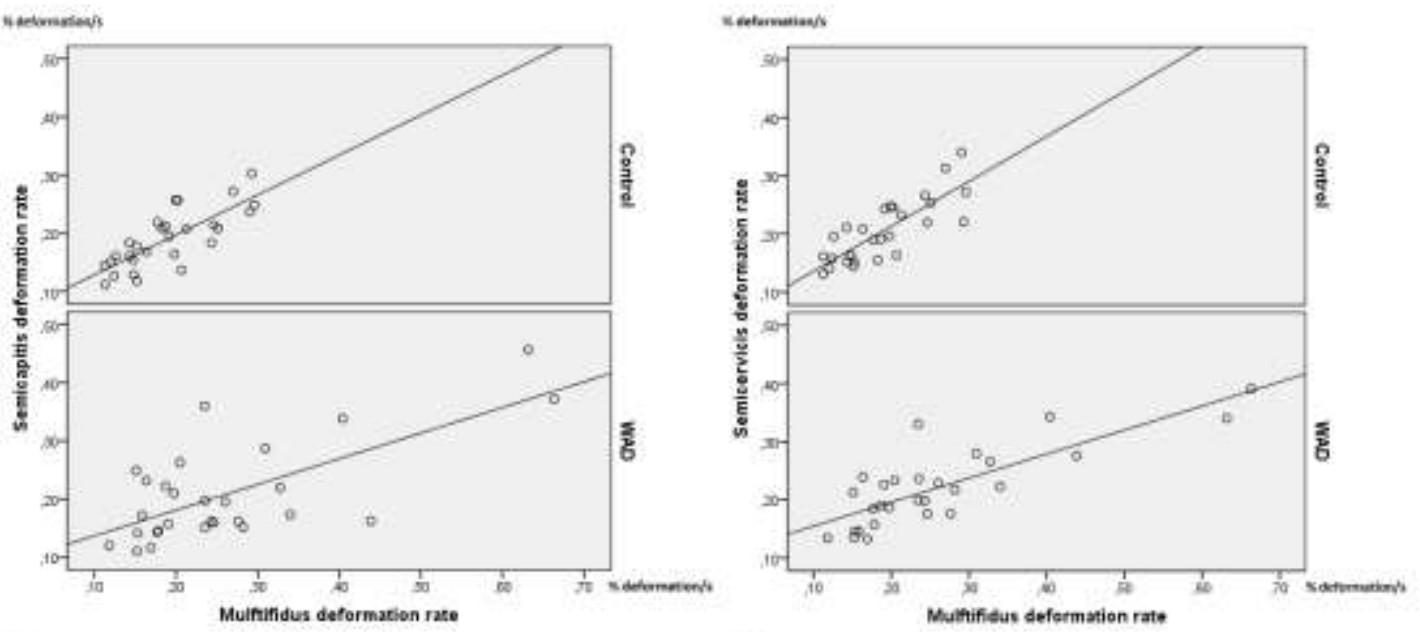

c)

d)

Fig. 2 a-d Linear relationships between the deformation rates of muscle pairs in women

Linear relationships between the deformation rates of muscle pairs in women based on the tenth arm elevation. a) Controls (top panel) exhibited a moderate relationship between the trapezius and multifidus $(\mathrm{MF})$ muscles $\left(\mathrm{R}^{2}=0.49\right)$ compared to a weak relationship in individuals with WAD (bottom panel) $\left(\mathrm{R}^{2}=0.11\right)$. b) Controls (top panel) exhibited a strong relationship between the splenius and MF muscles $\left(R^{2}=0.68\right)$ compared to a weak 
relationship in individuals with WAD (bottom panel) $\left(\mathrm{R}^{2}=0.07\right)$. c) Controls (top panel) and individuals with WAD (bottom panel) exhibited a moderate relationship between the semispinalis capitis and MF muscles (controls, $\mathrm{R}^{2}=0.58$; WAD, $\mathrm{R}^{2}=0.42$ ). d) Controls (top panel) and individuals with WAD (bottom panel) exhibited a strong relationship between the semispinalis cervicis and MF muscles (controls, $\mathrm{R}^{2}=0.65 ; \mathrm{WAD}, \mathrm{R}^{2}=0.64$ ).

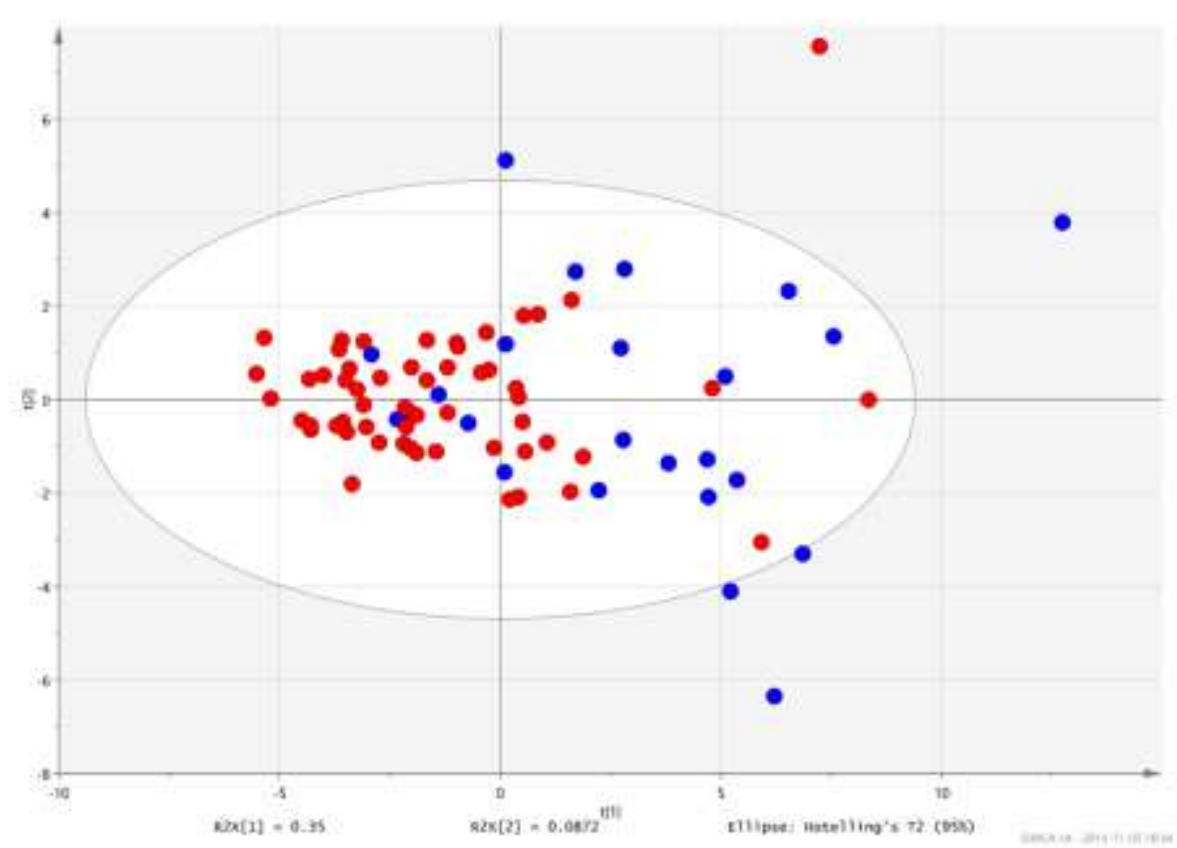

Fig. 3. a Score plot

Score plot for the first two components of the PCA model created for the 40 deformation and deformation rate variables. The plot shows score values for the principal component $t[1]$ on the $\mathrm{x}$-axis and the second component $\mathrm{t}[2]$ on the $\mathrm{y}$-axis. A score value, which does not have unit, gives the position of a certain observation on the drawn principal component. Observations of similar properties, as given by the measured variables, obtain comparable score values. Men (blue) had a more heterogenous spread and more outliers than women (red). Also, they tend to be situated more to the right, which indicates differences between men and women. 


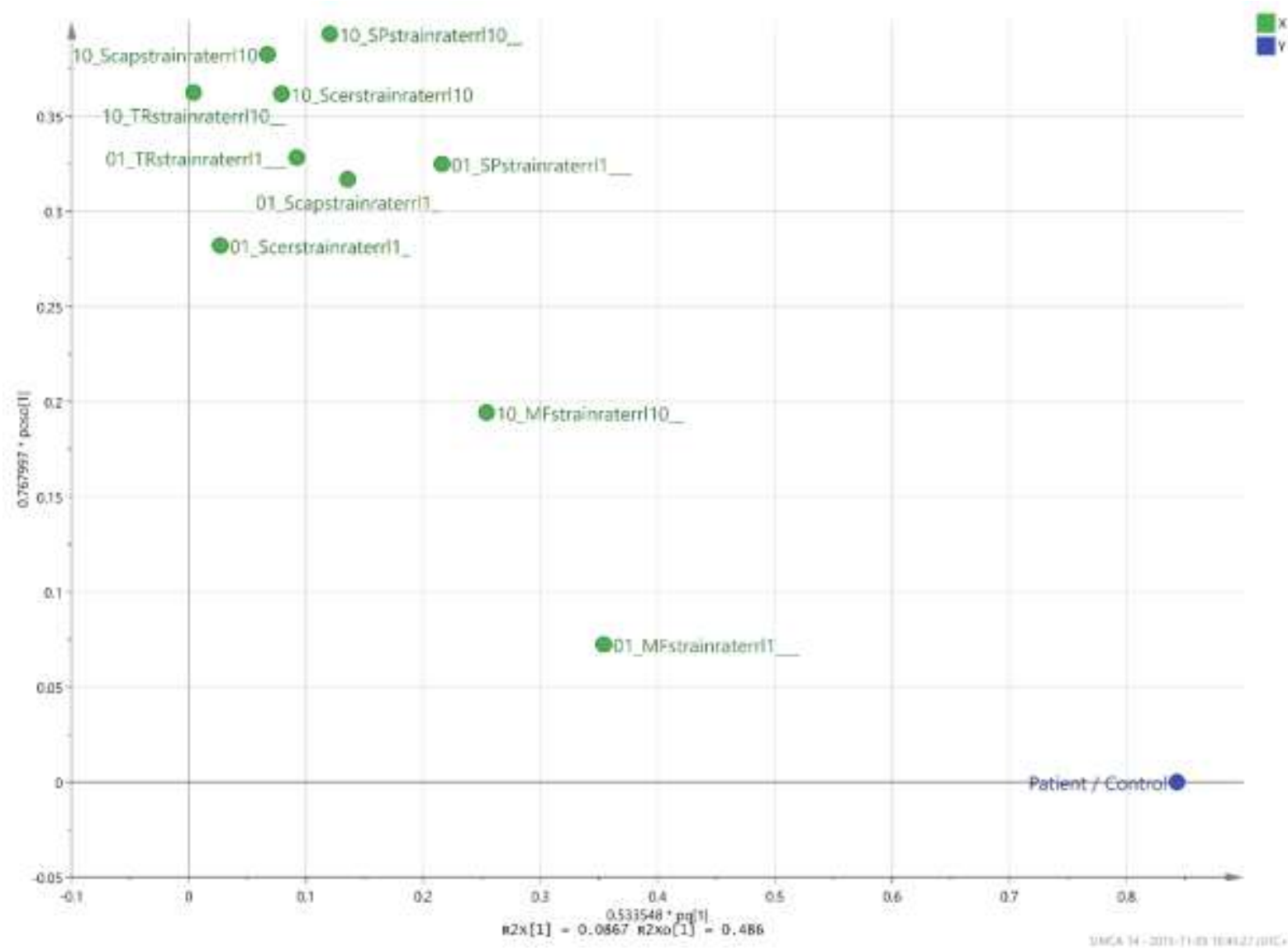

Fig. 3. b Loading plot

Loading plot for the OPLS-DA model, which separates individuals with WAD from controls.

The variables positioned closest to $\mathrm{Y}(\mathrm{WAD} / \mathrm{control})$ are the deformation rates for the multifidus muscle at the first and tenth arm elevations. This plot shows the loading vectors of the model; the correlated (important) loading is shown on the $\mathrm{x}$-axis and the orthogonal loading on the y-axis. Loading values are without unit, and express the importance of each variable in the model. There is one loading value for each of the variables that are included in the model. Loading values with higher values are more important than those that are close to zero. Abbreviations: strainrate, deformation rate; 01and rrl1, first arm elevation; 10 and rrl10, tenth arm elevation; TR, trapezius; SP, splenius capitis; Scap, semispinalis capitis; Scerv, semispinalis cervicis; MF, multifidus/rotatores. Example: 01_MFstrainraterrl1, multifidus deformation rate during first arm elevation. 


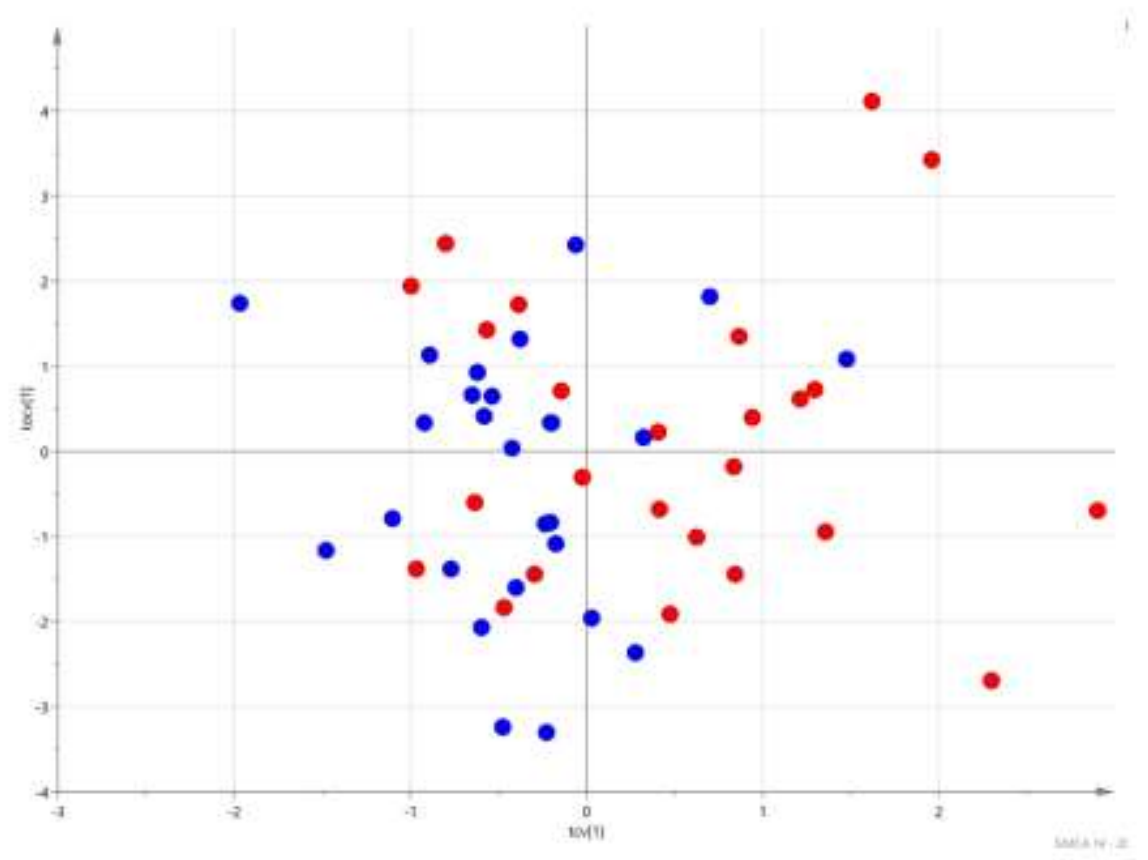

Fig. 3. c Cross-validated score plot

Cross-validated score plot for the OPLS-DA model in which ten deformation rate variables were used to separate patients from controls. The plot shows score values for the principal component $\mathrm{t}[1]$ on the $\mathrm{x}$-axis and the second component $\mathrm{t}[2]$ on the $\mathrm{y}$-axis. A score value, which does not have unit, gives the position of a certain observation on the drawn principal component. Observations of similar properties, as given by the measured variables, obtain comparable score values. The plot does not show a clear separation, but individuals with WAD (red) are mainly positioned to the right, which indicates differences between the control (blue) and WAD groups (red 
Supplement file 1. Muscle deformation (\% change in length) at the first $\left(1^{\text {st }}\right)$ and tenth $\left(10^{\text {th }}\right)$ arm elevation in the five dorsal neck muscles in the WAD and control groups, including total deformation area, elongation and shortening area with outliers excluded. 


\begin{tabular}{|c|c|c|c|c|c|c|c|c|c|}
\hline & & \multicolumn{4}{|c|}{ lst arm elevation } & \multicolumn{4}{|c|}{ 10th arm elevation } \\
\hline & & $\mathbf{n}$ & Control & $\mathbf{n}$ & WAD & $\mathbf{n}$ & Control & $\mathbf{n}$ & WAD \\
\hline Whole group & Test time ${ }^{\dagger}$ & 38 & $2.38(0.33)$ & 40 & $2.42(0.37)$ & 39 & $2.39(0.35)$ & 37 & $2.48(0.52)$ \\
\hline \multirow[t]{5}{*}{ Total area } & TR & 38 & $6.7(4.5)$ & 40 & $5.8(3.2)$ & 39 & $5.1(3.0)$ & 37 & $5.2(3.0)$ \\
\hline & SP & 38 & $7.8(5.2)$ & 40 & $9.1(5.1)$ & 39 & $7.7(5.1)$ & 37 & $8.2(5.5)$ \\
\hline & Scap & 38 & $9.0(5.4)$ & 40 & $10.5(6.4)$ & 39 & $9.1(6.2)$ & 37 & $10.3(6.7)$ \\
\hline & Scerv & 38 & $11.2(5.9)$ & 40 & $11.8(6.8)$ & 39 & $9.8(5.3)$ & 37 & $10.6(5.9)$ \\
\hline & MF & 38 & $14.2(10.7)$ & 40 & $12.0(5.6)$ & 39 & $9.7(5.4)$ & 37 & $9.9(4.7)$ \\
\hline \multirow[t]{5}{*}{ Elongation } & $\mathrm{TR}$ & 38 & $3.3(3.6)$ & 40 & $3.1(1.9)$ & 39 & $2.6(2.0)$ & 37 & $2.6(2.0)$ \\
\hline & SP & 38 & $3.2(2.7)$ & 40 & $3.8(2.6)$ & 39 & $3.0(2.1)$ & 37 & $3.6(3.2)$ \\
\hline & Scap & 38 & $4.6(3.6)$ & 40 & $4.8(3.8)$ & 39 & $4.0(3.6)$ & 37 & $4.5(4.4)$ \\
\hline & Scerv & 38 & $4.4(3.3)$ & 40 & $4.5(3.9)$ & 39 & $4.6(4.4)$ & 37 & $4.0(2.1)$ \\
\hline & MF & 38 & $5.4(5.2)$ & 40 & $4.6(3.1)$ & 39 & $2.8(2.0)$ & 37 & $2.6(2.1)$ \\
\hline \multirow[t]{5}{*}{ Shortening } & $\mathrm{TR}$ & 38 & $3.3(3.0)$ & 40 & $2.7(2.3)$ & 39 & $2.5(2.2)$ & 37 & $2.6(1.9)$ \\
\hline & SP & 38 & $4.7(4.1)$ & 40 & $5.7(5.6)$ & 39 & $4.6(4.6)$ & 37 & $4.6(3.3)$ \\
\hline & Scap & 38 & $4.8(3.6)$ & 40 & $5.6(4.9)$ & 39 & $5.1(4.3)$ & 37 & $5.7(4.3)$ \\
\hline & Scerv & 38 & $6.8(4.5)$ & 40 & $7.3(4.8)$ & 39 & $5.2(4.4)$ & 37 & $6.6(4.7)$ \\
\hline & MF & 38 & $8.9(7.8)$ & 40 & $7.3(4.5)$ & 39 & $6.9(4.7)$ & 37 & $7.3(5.0)$ \\
\hline Women & Test time $\dagger$ & 28 & $2.41(0.37)$ & 28 & $2.44(0.35)$ & 28 & $2.37(0.36)$ & 27 & $2.42(0.44)$ \\
\hline \multirow[t]{5}{*}{ Total area } & $\mathrm{TR}$ & 28 & $6.0(4.3)^{*}$ & 28 & $5.7(3.3)$ & 28 & $4.4(2.6)^{*}$ & 27 & $5.3(3.3)$ \\
\hline & SP & 28 & $6.2(3.2)^{*}$ & 28 & $8.0(3.7)$ & 28 & $5.8(3.2)^{*}$ & 27 & $8.4(5.2)$ \\
\hline & Scap & 28 & $8.2(4.4)^{*}$ & 28 & $9.1(5.1)$ & 28 & $6.7(3.1)^{*}$ & 27 & $9.4(6.4)$ \\
\hline & Scerv & 28 & $10.5(6.0)^{*}$ & 28 & $12.4(7.1)$ & 28 & $8.5(5.3)^{*}$ & 27 & $10.1(5.3)$ \\
\hline & MF & 28 & $11.7(8.2)^{*}$ & 28 & $11.4(5.4)$ & 28 & $7.5(3.8)^{*}$ & 27 & $9.8(4.9)$ \\
\hline \multirow[t]{5}{*}{ Elongation } & $\mathrm{TR}$ & 28 & $2.9(2.8)$ & 28 & $3.2(2.0)$ & 28 & $2.2(1.9)$ & 27 & $2.7(2.3)$ \\
\hline & SP & 28 & $2.6(2.2)$ & 28 & $3.8(2.6)$ & 28 & $2.6(1.8)$ & 27 & $3.8(3.1)$ \\
\hline & Scap & 28 & $4.0(3.4)$ & 28 & $4.3(3.2)$ & 28 & $2.7(2.2)$ & 27 & $4.0(4.5)$ \\
\hline & Scerv & 28 & $4.2(3.2)$ & 28 & $4.8(4.1)$ & 28 & $4.4(3.6)$ & 27 & $3.8(2.7)$ \\
\hline & MF & 28 & $5.0(5.6)$ & 28 & $4.5(3.2)$ & 28 & $2.4(1.9)$ & 27 & $2.9(2.3)$ \\
\hline \multirow[t]{5}{*}{ Shortening } & $\mathrm{TR}$ & 28 & $3.0(2.8)$ & 28 & $2.5(2.0)$ & 28 & $2.2(2.1)$ & 27 & $2.5(2.0)$ \\
\hline & SP & 28 & $4.2(4.0)$ & 28 & $5.3(5.2)$ & 28 & $3.2(2.6)$ & 27 & $4.6(2.9)$ \\
\hline & Scap & 28 & $4.2(2.7)$ & 28 & $4.8(4.2)$ & 28 & $4.0(3.2)$ & 27 & $5.4(4.0)$ \\
\hline & Scerv & 28 & $6.3(4.4)$ & 28 & $7.6(4.3)$ & 28 & $4.1(3.5)$ & 27 & $6.4(5.0)$ \\
\hline & MF & 28 & $6.7(3.5)$ & 28 & $6.9(4.1)$ & 28 & $5.1(3.6)$ & 27 & $6.9(5.0)$ \\
\hline Men & Test time ${ }^{\dagger}$ & 10 & $2.31(0.18)$ & 12 & $2.36(0.43)$ & 11 & $2.42(0.32)$ & 10 & $2.64(0.73)$ \\
\hline \multirow[t]{5}{*}{ Total area } & $\mathrm{TR}$ & 10 & $8.5(4.8)^{*}$ & 12 & $6.0(3.3)$ & 11 & $7.1(3.2)^{*}$ & 10 & $4.8(2.3)$ \\
\hline & SP & 10 & $12.2(7.3)^{*}$ & 12 & $11.8(6.9)$ & 11 & $12.3(6.1)^{*}$ & 10 & $7.7(6.4)$ \\
\hline & Scap & 10 & $13.1(6.6)^{*}$ & 12 & $13.6(8.1)$ & 11 & $15.2(7.9)^{*}$ & 10 & $12.6(7.4)$ \\
\hline & Scerv & 10 & $13.2(5.6)^{*}$ & 12 & $10.4(6.1)$ & 11 & $12.9(4.3)^{*}$ & 10 & $11.9(7.3)$ \\
\hline & MF & 10 & $21.5(14.0)^{*}$ & 12 & $13.4(5.9)$ & 11 & $15.2(5.1)^{*}$ & 10 & $10.2(4.9)$ \\
\hline \multirow[t]{5}{*}{ Elongation } & $\mathrm{TR}$ & 10 & $4.5(5.3)$ & 12 & $2.7(1.6)$ & 11 & $3.6(1.9)$ & 10 & $2.1(1.3)$ \\
\hline & SP & 10 & $4.6(3.8)$ & 12 & $4.1(2.8)$ & 11 & $4.0(2.7)$ & 10 & $3.2(3.4)$ \\
\hline & Scap & 10 & $6.4(3.8)$ & 12 & $6.0(5.0)$ & 11 & $7.4(4.3)$ & 10 & $5.9(4.0)$ \\
\hline & Scerv & 10 & $4.8(3.8)$ & 12 & $3.6(3.2)$ & 11 & $5.0(6.0)$ & 10 & $4.6(4.1)$ \\
\hline & MF & 10 & $6.4(3.9)$ & 12 & $5.0(2.8)$ & 11 & $3.8(2.0)$ & 10 & $1.7(1.3)$ \\
\hline \multirow[t]{5}{*}{ Shortening } & $\mathrm{TR}$ & 10 & $4.0(3.6)$ & 12 & $3.3(2.7)$ & 11 & $3.5(2.5)$ & 10 & $2.7(1.6)$ \\
\hline & SP & 10 & $6.1(4.3)$ & 12 & $6.8(6.6)$ & 11 & $8.3(6.6)$ & 10 & $4.4(4.3)$ \\
\hline & Scap & 10 & $6.7(5.2)$ & 12 & $7.6(5.9)$ & 11 & $7.8(5.1)$ & 10 & $6.6(5.2)$ \\
\hline & Scerv & 10 & $8.4(4.7)$ & 12 & $6.8(6.0)$ & 11 & $7.9(5.1)$ & 10 & $7.3(5.2)$ \\
\hline & $\mathrm{MF}$ & 10 & $15.1(12.5)$ & 12 & $8.4(5.5)$ & 11 & $11.4(4.0)$ & 10 & $8.5(5.2)$ \\
\hline
\end{tabular}


Data are means \pm SD. Muscle deformation (\% change in length) at the first $\left(1^{\text {st }}\right)$ and tenth $\left(10^{\text {th }}\right)$ arm elevation in the five dorsal neck muscles in the WAD and control groups. Total area represents both elongation and shortening during arm elevation. †Test time in seconds for the first and tenth arm elevation. There were significant differences in deformation total area between women and men in the control group at the first and tenth arm elevations.

$*(\mathrm{p}>0.001)$. 
Supplementary file 2. Muscle deformation rate (\% deformation/s) during the first $\left(1^{\text {st }}\right)$ and tenth $\left(10^{\text {th }}\right)$ arm elevation in the five dorsal neck muscles in the WAD and control groups with outliers excluded.

\begin{tabular}{cllllllllll}
\hline & \multicolumn{9}{c}{ 1st arm elevation } & \multicolumn{4}{c}{ 10th arm elevation } \\
& & $\mathbf{n}$ & Control & n & WAD & n & Control & n & WAD \\
\hline \multirow{3}{*}{ Whole group TR } & 35 & $0.15(0.06)$ & 38 & $0.15(0.06)$ & 36 & $0.14(0.05)$ & 40 & $0.14(0.05)$ \\
& SP & 35 & $0.19(0.07)$ & 38 & $0.19(0.06)$ & 36 & $0.20(0.07)$ & 40 & $0.20(0.08)$ \\
& Scap & 35 & $0.20(0.06)$ & 38 & $0.21(0.07)$ & 36 & $0.21(0.07)$ & 40 & $0.22(0.08)$ \\
& Scerv & 35 & $0.23(0.06)$ & 38 & $0.23(0.06)$ & 36 & $0.22(0.06)$ & 40 & $0.24(0.08)$ \\
& MF & 35 & $0.22(0.08)$ & 38 & $0.27(0.10)$ & 36 & $0.21(0.08)$ & 40 & $0.28(0.15)$ \\
& & & & & & & & & \\
Women & TR & 28 & $0.13(0.05)$ & 28 & $0.13(0.03)$ & 28 & $0.13(0.05)$ & 28 & $0.13(0.05)$ \\
& SP & 28 & $0.16(0.05)$ & 28 & $0.18(0.06)$ & 28 & $0.17(0.05)$ & 28 & $0.18(0.07)$ \\
& Scap & 28 & $0.18(0.05)$ & 28 & $0.20(0.07)$ & 28 & $0.19(0.05)$ & 28 & $0.21(0.09)$ \\
& Scerv & 28 & $0.20(0.05)$ & 28 & $0.21(0.05)$ & 28 & $0.20(0.05)$ & 28 & $0.22(0.07)$ \\
& MF & 28 & $0.20(0.06)$ & 28 & $0.24(0.09)^{*}$ & 28 & $0.19(0.06)$ & 28 & $0.26(0.13)^{*}$ \\
& & & & & & & & & \\
Men & TR & 7 & $0.21(0.04)^{*}$ & 10 & $0.19(0.07)^{*}$ & 8 & $0.18(0.04)^{*}$ & 12 & $0.16(0.04)^{*}$ \\
& SP & 7 & $0.28(0.06)^{*}$ & 10 & $0.22(0.05)^{*}$ & 8 & $0.28(0.07)^{*}$ & 12 & $0.24(0.10)^{*}$ \\
& Scap & 7 & $0.28(0.06)^{*}$ & 10 & $0.24(0.04)^{*}$ & 8 & $0.28(0.09)^{*}$ & 12 & $0.23(0.05)^{*}$ \\
& Scerv & 7 & $0.29(0.05)^{*}$ & 10 & $0.27(0.08)^{*}$ & 8 & $0.27(0.06)^{*}$ & 12 & $0.27(0.09)^{*}$ \\
& MF & 7 & $0.31(0.09)^{*}$ & 10 & $0.33(0.11)^{*}$ & 8 & $0.28(0.09)^{*}$ & 12 & $0.34(0.16)^{*}$ \\
& & & & & & & & & & \\
\hline
\end{tabular}

Data are mean \pm SD. Muscle deformation rate (\% deformation/s) during the first $\left(1^{\text {st }}\right)$ and tenth $\left(10^{\text {th }}\right)$ arm elevation in the five dorsal neck muscles in the WAD and control groups. Abbreviations; TR, trapezius; SP, splenius capitis; Scap, semispinalis capitis; Scerv, semispinalis cervicis; MF, multifidus/rotatores. There were significant differences in deformation rate between women and men in both group. There were significant differences between the WAD and control group in the multifidus muscle during the first and tenth (only between women) arm elevations.

$* \mathrm{p}<0.05$ 